\title{
EDUCATION ONLINE
}

\section{Модели проектирования и функционирования цифровых образовательных сред}

Научная статья

DOI: $10.31992 / 0869-3617-2021-30-1-144-155$

Соловов Александр Васильевич - канд. техн. наук, проф., а_solovov@mail.ru

Меньшикова Анастасия Александровна - канд. техн. наук, доцент, nastya.menshikova@gmail.com Самарский национальный исследовательский университет им. академика С.П. Королева, Самара, Россия

Адрес: 443086, г. Самара, Московское шоссе, 34

Аннотация. Многие учебнье заведения, оченивая свои перспективы, планируют развитие дистаниионньх образовательных услуг с использованием собственных электронньх информачионно-образовательньх сред (ЭИОС ). При создании и функиионировании ЭИОС образовательного учреждения (ОУ) возникает ряд вопросов, связанных со структурньми, маркетинговыми, кадровыми и прочими решениями. Цель данной статьи - исследование организачионно-технических и дидактических аспектов ЭОИС ОУ. Методология исследования базируется на методах системного анализа, кибернетики, педагогчческой психологии и дидактики.

Предложена кониептуальная модель ЭИОС ОУ как организачионно-технической системьь. В её состав входят: подсистема маркетинга, комплекс технических средсть, различные виды обеспечений и организачионная подсистема. Определены основные функиии этих подсистем и их различных компонентов.

Сформирована дидактическая модель типового комплекса иифровьх образовательньхх ресурсов. В рамках этой модели всё многообразие иифровьхх образовательных ресурсов по каждой учебной дисчиплине интегрируется в комплексы, которые обеспечивают полноченную проработку учебного материала на разных челевых уровнях усвоения- от первоначального знакомства до решения нетиповьх профессионально ориентированных задач.

С позичий педагогчческой психологии и кибернетики показана высокая значимость обратных связей в ЭИОС ОУ. Аля триадь «Педагог - Обучаюшая программа - Обучаемый» предложена классификачия обратных связей (внутренние и внешние). Указаны граничь использования автоматизачии при формировании обратных связей в отличие от иных (некомпьютерных ) откликов на учебную деятельность обучаемьх. Показань роль и место обратных связей в «цирровых следах» учашихсл и преподавателей и намечены направления использования этих данных в системах искусственного интеллекта. 
Ключевые слова: электроннал информачионно-образовательная среда, иифровые образовательные ресурсы, электронное обучение, обратнье связи В автоматизачии обучения, онлайн-обучение, искусственный интеллект в обучении, илирровые следы

Аля илтированил: Соловов А.В., Меньшикова А.А. Модели проектирования и функционирования цифровых образовательных сред // Высшее образование в России. 2021. Т. 30. № 1. C. 144-155. DOI: 10.31992/0869-3617-2021-30-1-144-155

\section{Models for the Design and Operation of Digital Educational Environments}

Original article

DOI: 10.31992/0869-3617-2021-30-1-144-155

AlexanderV.Solovov - Cand. Sci. (Engineering), Prof., a_solovov@mail.ru

Anastasia A.Menshikova - Cand. Sci. (Engineering), Assoc. Prof., nastya.menshikova@gmail.com Samara National Research University, Samara, Russia

Address: 34, Moskovskoe schosse, Samara, 443086, Russian Federation

Abstract. Many educational institutions, assessing their prospects, plan to develop distance educational services using their own electronic and information educational environments (EIEE). During creating and operating EIEE of educational institution (EI), a number of questions arise related to structural, marketing, personnel and other decisions. The purpose of this article is to research the organizational, technical and didactic aspects of the EIEE EI. The methodology of the research is based on methods of system analysis, cybernetics, pedagogical psychology and didacticism.

A conceptual model of the EIEE EI as an organizational and technical system has been proposed. It includes a marketing subsystem, a set of technical tools, various types of security and an organizational subsystem. The main functions of these subsystems and their various components have been identified.

A didactic model of a typical complex of digital educational resources has been developed. Within this model, the diversity of digital educational resources across each academic discipline is integrated into complexes that provide a complete study at different target levels of assimilation, from initial acquaintance to solving uncharacteristic professionally oriented tasks.

From the point of view of pedagogical psychology and cybernetics, the high importance of feedback in EIEE EI is shown. The classification of feedbacks (internal and external) is proposed for the triad "Teacher - Teaching Program - Learner". The limits of the use of automation in the formation of feedbacks are specified, as opposed to other (non-computer) responses to students' educational activities. The role and place of feedback in the "digital footprints" of students and teachers is shown and the directions for the use of this data in artificial intelligence systems are outlined.

Keywords: electronic information and education environment, digital educational resources, e-learning, feedback in learning automation, online learning, artificial intelligence in learning, digital footprints

Cite as: Solovov, A.V., Menshikova, A.A. (2021). Models for the Design and Operation of Digital Educational Environments. Vysshee obrazovanie v Rossii = Higher Education in Russia. Vol. 30, no. 1, pp. 144-155, doi: 10.31992/0869-3617-2021-30-1-144-155 (In Russ., abstract in Eng.). 


\section{Введение}

Успешное развитие цифровой экономики невозможно без компетентных кадров. Аля их подготовки нужны адекватные современным цифровым вызовам образовательные системы. Создание таких систем в России регулируется государственным приоритетным проектом «Современная цифровая образовательная среда», в паспорте которого определены основные задачи, пути и средства реализации проекта ${ }^{1}$. Ключевая цель проекта - создать условия для непрерывного образования на базе цифровых платформ онлайн-образования, обеспечить возможность обучения граждан по индивидуальному учебному плану в течение всей жизни - в любое время и в любом месте. Аля реализации этой цели созданы и развиваются федеральные площадки онлайн-обучения на базе различных программных платформ - как отечественных (https://openedu.ru/; https://elearning.hse. ru/npoo_project и ap.), так и многочисленных зарубежных (см. обзор на http://www. library.fa.ru/page.asp?id=183).

Многие учебные заведения, оценивая свои перспективы, планируют развитие дистанционных образовательных услуг на основе технологий онлайн-обучения. При этом в соответствии со статьёй 16 Федерального Закона об образовании в в учебном заведении «должны быть созданы условия для функционирования электронной информационно-образовательной среды, включающей в

${ }^{1}$ Паспорт приоритетного проекта «Современная цифровая образовательная среда в Российской Федерации». Утверждён президиумом Совета при Президенте Российской Федерации по стратегическому развитию и приоритетным проектам 25 октября 2016. URL: http://static. government.ru/media/files/8SiLmMBgjAN89vZbUUtmuF5IZYfTvOAG.pdf (дата обращения: 20.12.2020).

2 Федеральный закон "Об образовании в Российской Федерации” N 273-ФЗ от 29 декабря 2012 года с изменениями 2020 года. URL: http://zakon-ob-obrazovanii.ru/ (Аата обращения: 20.12.2020). себя электронные информационные ресурсы, әлектронные образовательные ресурсы, совокупность информационных технологий, телекоммуникационных технологий, соответствующих технологических средств и обеспечивающей освоение обучающимися образовательных программ в полном объёме независимо от места нахождения обучающихся». К тому же ФГОС фактически предписывают вузу иметь собственную электронную информационно-образовательную среду (ЭИОС), а пандемия коронавируса весной 2020 г. сделала это требование одним из важнейших условий успешного функционирования учебных заведений․․ При этом многие российские учащиеся выражают неудовлетворённость цифровой инфраструктурой образовательных учреждений (ОУ) [1]. Заметим, что и зарубежные университеты, несмотря на успешную экспансию в систему образования MOOK-платформ Coursera, Udacity, EdX и др., свои перспективы связывают именно с развитием собственных университетских ЭИОС [2].

При создании и функционировании ЭИОС ОУ возникает ряд вопросов, связанных со структурными, маркетинговыми, кадровыми и прочими решениями. Цель данной статьи - исследование организационно-технических и дидактических аспектов ЭОИС ОУ. Методология исследования базируется на методах системного анализа, кибернетики, педагогической психологии и дидактики. В основу исследований положены идеи авторов, предложенные ими и реализованные в более ранних работах применительно к автоматизации проектирования, производства и обучения [3-5] и адаптированные к нынешним трендам в сфере цифровизации образования.

\footnotetext{
3 Уроки «Стресс-теста». Вузы в условиях пандемии и после неё. Аналитический доклад Министерства науки и высшего образования РФ. Июнь 2020. URL: https://ftp.skolkovo.ru/web_ team/School/2020/03072020_report.pdf (Аата обращения: 20.12.2020).
} 


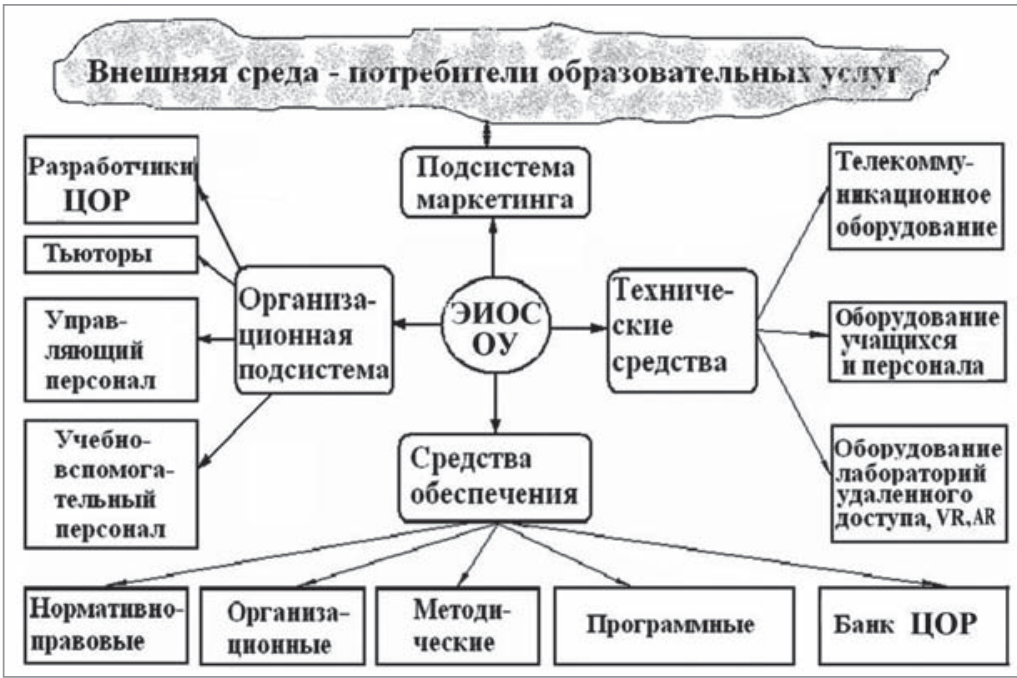

Puc. 1. Структура ЭИОС ОУ как организационно-технической системы Fig. 1. The structure of the EIEE EI as an organizational and technical system

ЭИОС ОУ как организационнотехническая система

Нередко, говоря об ЭИОС, имеют в виду программную оболочку для управления содержанием и/или процессом обучения (Learning Content Management System LCMS, Learning Management System - LMS, программные платформы для размещения видеокурсов). Однако с позиций системного подхода целесообразно рассматривать ЭИОС как организационно-техническую систему, в состав которой в качестве основных подсистем входят подсистема маркетинга, комплекс технических средств, средства обеспечения и организационная подсистема (Puc. 1).

Подсистема маркетинга. Зачем она нужна в ЭИОС? Предположим, что вы менеджер ОУ. Вы должны чётко знать, кто принесёт вам деньги. Кто клиенты и сколько их? Какие услуги они хотят получить? Каким должно быть содержание обучения? Какие целесообразно использовать технологии обучения? Ответы на эти и другие подобные вопросы необходимо иметь, прежде чем приступать к формированию и развитию ЭИОС ОУ, поскольку борьба за клиентов (обучающихся) ныне ведётся не только коммерческими, но и государственными ОУ.
Комплекс технических средсть ЭИОС ОУ включает в качестве основных компонентов телекоммуникационное оборудование (в том числе серверное), компьютерное оборудование учащихся и персонала, оборудование лабораторий удалённого доступа, системы виртуальной и дополненной реальности (VR и AR). И если вопросы комплектации и организации работы компьютерного и телекоммуникационного оборудования можно решать на основе типовых подходов, то в создании и использовании лабораторий удалённого доступа, систем VR и AR, несмотря на отдельные достижения, пока ещё вряд ли можно рассчитывать на типовые решения. С оборудованием учащихся и персонала (стационарными ПК, мобильными устройствами) ныне практически нет проблем. Если же в ОУ существуют трудности с телекоммуникационными средствами, серверами для хранения контента и другими техническими средствами общего назначения, то ныне вполне возможно перейти на аутсорсинг облачных ресурсов [6].

Средства обеспеченил. Включают следующие компоненты.

Нормативно-правовье документы, определяющие, в частности, договорные отношения с разработчиками онлайн-курсов и 
финансовые нормативы работы ЭИОС ОУ. Как заинтересовать разработчиков курсов не только готовить их, но и сопровождать в дальнейшем - обновлять и корректировать содержание? Как оценивать работу тьюторов? В ответ на призывы внедрять технологии онлайн-обучения преподаватели часто спрашивают: «А как это повлияет на заработок, ведь платят нам за аудиторные часы?» Эти и многие другие вопросы: отчисления в ОУ как в базовую организацию, в фонд развития ЭИОС, нормативы оплаты труда управляющего и учебно-вспомогательного персонала и т.п. - должны быть определены в нормативно-правовой документации.

Организачионное обеспечение включает положение об ЭИОС ОУ, штатное расписание, должностные инструкции. Сюда же входит и текущая организационная документация - приказы, указания и т.п.

Методическое обеспечение - это комплект документов, описывающих порядок взаимодействия обучающихся и персонала между собой, с техническими, программными и другими компонентами ЭИОС. В документах методического обеспечения определяют различные регламенты взаимодействия (например, как часто тьютор должен просматривать в онлайн-курсах и оценивать выполненные задания, давать ответы на вопросы учащихся и т.п.), что придаёт учебному процессу чёткость и порядок.

Программное обеспечение ЭИОС должно включать программный инструментарий Аля подготовки электронных ресурсов (в том числе авторскую систему и/или LCMS), репозитарий цифровых образовательных ресурсов, средства управления дистанционным учебным процессом (LMS), системы синхронного взаимодействия для проведений вебинаров и консультаций, программы записи и демонстрации видеолекций и т.п.

Банк ЦОР (цифровых образовательных ресурсов) - это, пожалуй, самый важный компонент средств обеспечения ЭИОС. Ведь это тот товар, который ЭИОС ОУ предлагает на рынке образовательных услуг, например, в формате онлайн-курсов. И не случайно поэтому значительная часть научно-методических разработок в сфере электронного обучения посвящена вопросам создания ЦОР.

Организаиионнал подсистема (персонал ЭИОС ОУ) включает в свой состав разработчиков онлайн-курсов (авторов содержания, методистов, инженеров-технологов), тьюторов (преподавателей, ведущих обучение), управляющий персонал (менеджеров ЭИОС), учебно-вспомогательный персонал (диспетчеров учебного процесса, специалистов по поддержке технического, программного и других средств обеспечения). Организационная подсистема является одним из важнейших компонентов ЭИОС, её формирование и развитие - это проблема, заслуживающая специального обсуждения [7].

\section{Аидактическая модель комплексов ЦОР}

В ходе исследований по проблемам методологии науки было предложено различать явные и неявные знания [8]. В дальнейшем в связи с активизацией исследований проблем искусственного интеллекта, в частности экспертных систем, эти вариации знания были названы артикулируемыми и неартикулируемыми [9].

Артикулируемая часть знания относительно легко подааётся превращению в информацию, которая является удобным средством передачи знаний от учителя к ученику. Неартикулируемая часть знания представляет собой тот неосязаемый, но очень важный дичностный компонент знания, который в ряде исследований принято называть компетенциями [10]. Эта часть знания охватывает умения, навыки, интуитивные образы и другие формы личностного опыта, которые не могут быть «переданы» непосредственно от учителя $\mathrm{k}$ ученику. Они могут быть «добыты» учеником лишь в ходе самостоятельной учебной деятельности по решению практических задач.

В исследованиях проблематики искусственного интеллекта выделяют два больших класса компьютерных систем - системы декларатив- 
ного и процедурного типов [11]. Следуя этой классификации, будем называть ЦОР для поддержки процесса освоения артикулируемой части знания декларативными. К их числу могут быть отнесены системы, позволяющие накапливать, хранить и передавать информацию учебного назначения с помощью заранее подготовленных алгоритмов обучения.

ЦОР для поддержки процесса освоения неартикулируемой части знания будем называть процедурными. Эти системы не содержат овеществлённое знание в виде информации. Они построены на основе математических моделей, которые позволяют учащимся получать (добывать) знания о свойствах изучаемых объектов или процессов.

В качестве ещё одного из оснований классификации ЦОР будем использовать следующую рубрикацию этапов познавательной учебной деятельности:

1) восприятие, первоначальное знакомство с учебным материалом;

2) осмысление и фиксация знаний;

3) формирование личностного опыта (умений, навыков, профессионально-ориентированной интуиции);

4) проектно-исследовательская, поисковая учебная деятельность.

В соответствии с этими этапами ЦОР можно классифицировать на четыре основные группы.

Первая группа включает ЦОР декларативного типа: электронные копии печатных материалов, графические, аудио- и видеоматериалы, VR, AR (виртуальная и дополненная реальность) и другой мультимедиаконтент. Электронные копии печатных материалов обычно содержат теорию по теме в виде учебного текста и графических иллюстраций к нему, рекомендации для преподавателей и учащихся, сборники задач для других видов ЦОР. Особо выделим столь модные в последнее время видеолекции, в которые можно интегрировать различные учебные материалы, а не только «говорящую голову». Мультимедиаконтент здесь крайне важен для формирования в сознании учащихся «правильного» образа изучаемого объекта или процесса. Аидактический потенциал этих видов ЦОР первоначальное знакомство с учебным материалом (его восприятие).

Bторую группу ЦОР также отнесём к средствам декларативного типа. Это электронные учебники, виртуальные учебные кабинеты и системы компьютерного тестирования, основные дидактические функции которых осмысление, закрепление и контроль знаний. Наиболее важным режимом учебной работы с такими ЦОР является тренинг по теории, в ходе которого учащемуся предъявляются задания тренировочных упражнений, последовательность и тип которых соответствуют логике усвоения учебного материала и рекомендациям психологических концепций обучения. После выполнения каждого упражнения следует сообщение о правильности ответа, предоставляется возможность посмотреть правильный ответ и соответствующие комментарии (разъяснение типовых ошибок, подсказки и т.п.). Роль комментариев нередко выполняют фрагменты учебной информации. Таким образом, учащийся вовлекается в активную когнитивную деятельность по осмыслению и закреплению учебного материала [12].

B mретью группу ЦОР могут входить интеллектуальные тренажёры, виртуальные учебные лаборатории и другие подобные компьютерные системы, отличительными особенностями которых являются математические модели изучаемых объектов или процессов и дидактический интерфейс, поддерживающий учащихся при решении специально подобранных учебных задач в режиме управляемого детерминированного исследования. Основное дидактическое назначение этих средств поддержки обучения - формирование и развитие неартикулируемой части знаний (профессионально-ориентированных умений, навыков, интуиции), исследование свойств изучаемых объектов или процессов [12; 13$]$.

Четвёртую группу составляют компьютерные системы автоматизации профессиональной деятельности или их учебные аналоги, например, системы автоматизации 


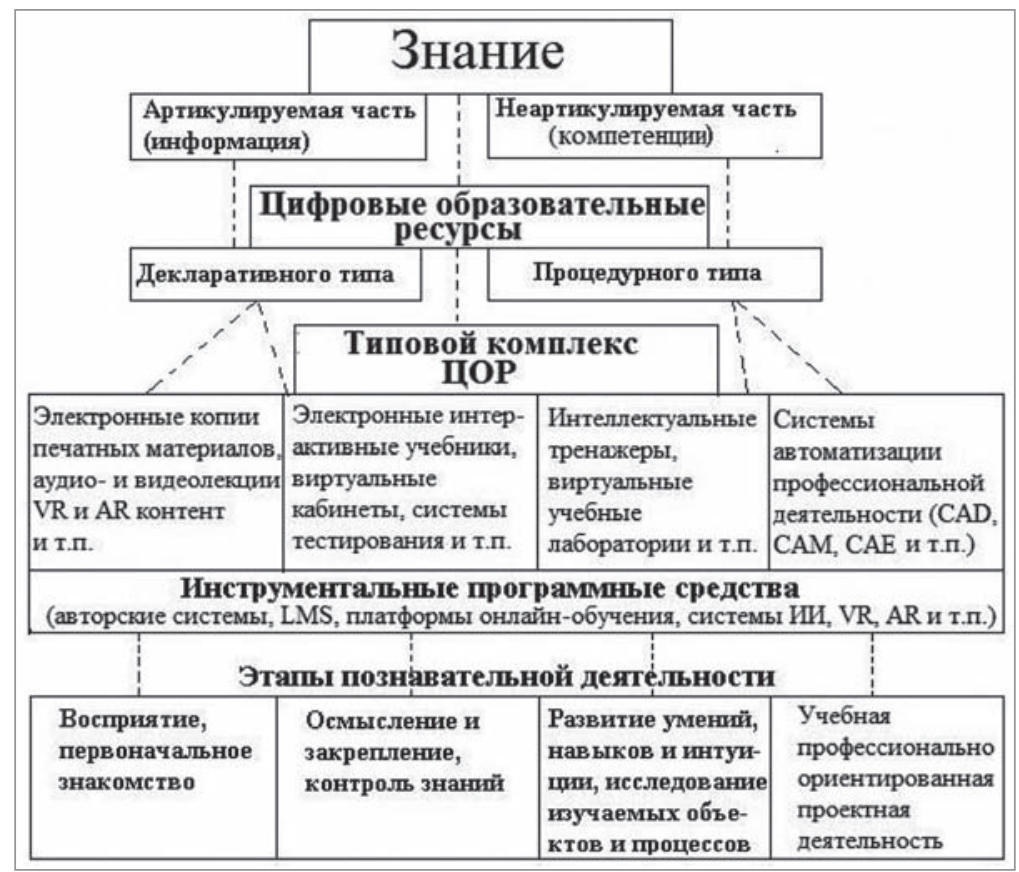

Puc. 2. Аидактическая модель комплекса цифровых образовательных ресурсов Fig. 2. Didactic model of the digital educational resource complex

проектирования, производства, инженерных расчётов (CAD, CAM, CAE) и т.п. Они могут использоваться учащимися для решения различных задач по изучаемой теме, возникающих, например, в ходе курсового или дипломного проектирования. Процесс учебной работы проходит при этом в режиме свободного исследования и близок по своему характеру к профессиональной деятельности специалиста.

Наиболее эффективным в дидактическом плане является интеграция рассмотренных групп ЦОР по учебной дисциплине в комплексы автоматизированных дидактических средств (Рис. 2). При этом рациональная, дидактически обоснованная последовательность обучения предполагает следующий порядок учебной работы с таким комплексом ЦОР:

1) первоначальное знакомство с учебным материалом с помощью электронных копий печатных материалов, аудио- и видеозаписей, видеолекций, VR, AR и другого подобного мультимедиаконтента;
2) осмысление и закрепление теории с помощью электронных учебников, виртуальных учебных кабинетов, контроль знаний по теории с помощью систем компьютерного тестирования;

3) формирование и развитие практических умений, профессионально-ориентированной интуиции на тренажёрах, проведение учебных исследований в виртуальных лабораториях;

4) решение профессионально-ориентированных учебных задач по тематике учебной дисциплины в курсовом и дипломном проектировании с помощью систем автоматизации профессиональной деятельности.

Таким образом, различным электронным компонентам комплекса ЦОР определена своя дидактическая ниша в соответствии с их возможностями.

\section{Обратные связи в ЭИОС}

С позиций педагогической психологии объектом обучения является психика. Один 
из краеугольных законов этой науки говорит, что психика проявляется, формируется и развивается только в деятельности. Исходя из этого, понятие «обучение» нередко определяют как управление познавательной деятельностью учащихся с целью формирования у них конкретных знаний, умений и навыков, развития личностных качеств.

В соответствии с постулатами общей кибернетической теории управления в любых циклических замкнутых системах управления, в том числе и в педагогических, должны быть реализованы следующие функции:

1) формирование целей управления;

2) установление исходного состояния объекта (субъекта) управления;

3) определение программы воздействий, предусматривающей основные переходные состояния объекта (субъекта) управления;

4) систематический сбор информации обратной связи;

5) переработка информации обратной связи с целью выработки и реализации корректирующих воздействий.

C позиций кибернетики традиционные классно-урочные методы обучения недостаточно эффективны, особенно при сборе информации обратной связи и выработки корректирующих воздействий. Они не обеспечивают самоконтроля знаний, дают мало информации преподавателю о том, как учащийся усваивает знания, не в полной мере учитывают индивидуальные особенности учащихся.

В то же время психологи считают, что процесс обучения наиболее эффективен, когда учащийся в процессе учебной деятельности примерно каждые полминуты получает сигнал «Аа» или «Нет». «Аа»позитивный сигнал, означает, что правильно усвоил учебный материал (или способ действия), следуй дальше. «Нет»- негативный сигнал, не усвоил, неверно действуешь. Остановись, разберись, пойми. Аишь после этого следуй дальше [14]. В традиционном классно-урочном формате обучения препо- даватель не может так оперативно и часто контролировать и корректировать деятельность учащихся. Поэтому указанные выше функции управления наиболее полно могут быть реализованы лишь в процессе автоматизированного обучения.

Остановимся более подробно на особенностях обратной связи, присущих обучению с помощью компьютеров. Обратную связь (ОС) в триаде «Педагог - Обучающая программа - Обучаемый» можно разделить на два вида: внутренняя и внешняя.

Внутренняя ОС - это информация, которая поступает от обучающей программы к учащемуся в ответ на его действия при выполнении упражнений. Она предназначена Аля самокоррекиии учащимся своей учебной деятельности. Понятие внутренней ОС имеет исключительно важное значение для автоматизации процесса обучения. Внутренняя ОС даёт учащемуся возможность сделать осознанный вывод об успешности или ошибочности учебной деятельности. Она побуждает его к рефлексии, является стимулом к дальнейшим действиям, помогает оценить и скорректировать результаты учебной деятельности. Различают консультирующую и результативную внутреннюю ОС. Консультация может быть разной: помощь, разъяснение, подсказка, наталкивание и т.п. Результативная ОС также может быть различной: от «верно - неверно» до демонстрации правильного результата или способа действия.

Внешняя ОС должна предоставлять преподавателю возможность получать объективную количественную оценку учебной деятельности каждого учащегося и статистику по учебной работе всей группы. Преподаватель должен анализировать не только итоговую оценку, но и путь, по которому продвигался учащийся в ходе изучения учебного материала или решения учебной задачи. Такой анализ позволит оказывать более дифференцированную помощь при проведении индивидуальных консультаций. Вовсе не обязательно, чтобы внешняя ОС была опе- 


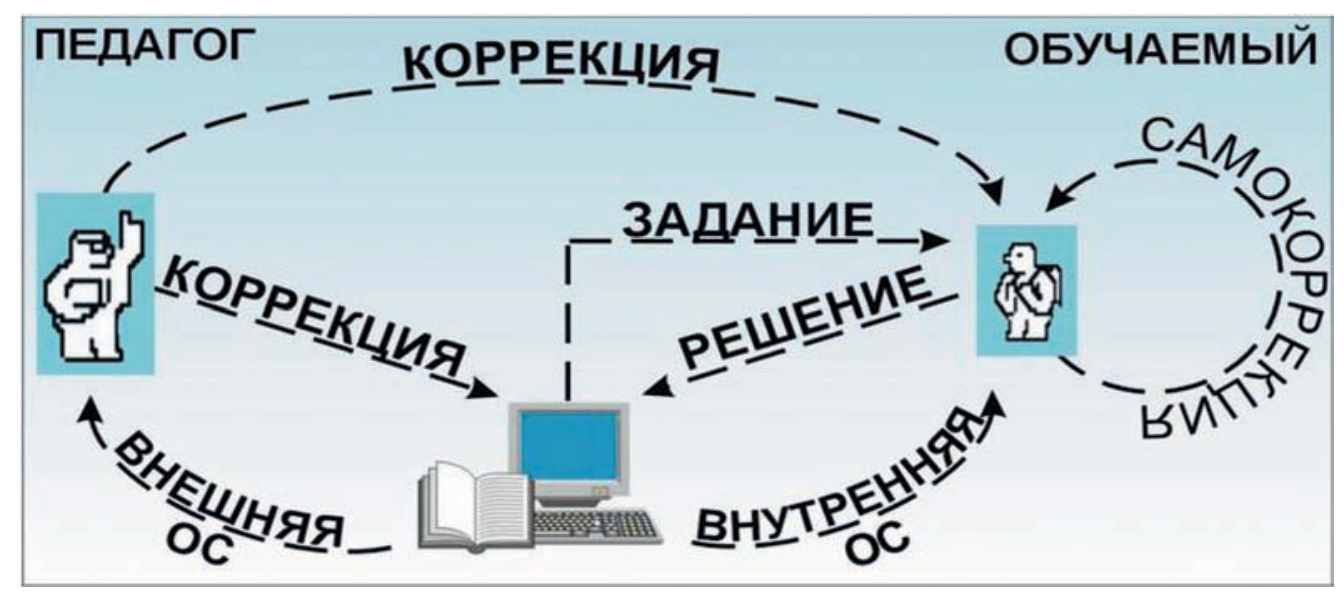

Puc. 3. Схема взаимодействия в триаде «Педагог - Обучающая программа - Обучаемый» Fig. 3. Interaction Scheme in the Triad "Educator - Learning Program - Learner"

ративной. Анализ информации внешней ОС может быть отсроченным, а коррекция по его результатам может проводиться в ходе групповых или индивидуальных консультаций и при совершенствовании обучающей программы (Рuc. 3).

Попытки автоматизировать процесс обучения в плане формирования обратных связей предпринимались давно. Важным методологическим базисом автоматизированных обучающих систем с разным уровнем автоматизации - от печатных учебных пособий и простейших механических устройств контроля знаний до современных компьютеров - издавна является теория программированного обучения. В основу этой теории положена концепция бихевиоризма. В бихевиоризме (от лат. behavior - поведение) не рассматриваются внутренние процессы человеческого мышления. Изучается поведение, которое трактуется как сумма реакций на какие-либо ситуации. Несмотря на острую критику за принципиальное невмешательство в мышление учащегося (бихевиористы управляют дишь его поведением), теория программированного обучения получила широкое распространение и была реализована в ряде технических обучающих устройств. И в настоящее время универсальная схема этой теории, выражаемая форму- лой $\mathbf{C} \rightarrow \mathbf{P} \rightarrow$ П, где $\mathbf{C}$ - ситуация; $\mathbf{P}$ - реакция; П - подкрепление, в её линейной, разветвлённой или адаптивной форме является стержневым әлементом многих компьютерных обучающих программ [5;12].

Однако следует чётко понимать, что универсального психологического механизма усвоения знаний не существует. Человеческая психика многообразна в своих проявлениях и не вписывается в схему. Поэтому при проектировании сценариев учебной работы в различных компонентах ЦОР (см. рис. 2) целесообразно учитывать характеристики целевых групп учащихся и цели обучения. Например, если требуется обучить операторов и при этом приходится применять армейский принцип «Не знаешь - научим, не хочешь - заставим», то уместно в полной мере использовать жёсткую схему линейного программирования. Там, где необходимы размышления и умственные действия, более подходящими могут оказаться другие теории обучения (см. соответствующий обзор в книге [12]).

Могут ли быть другие, неавтоматизированные обратные связи в ЭИОС? Аа, конечно! Это отклики (оценки, корректировки и т.п.) на учебную деятельность учащихся от преподавателей, от других учащихся, от родителей и т.п., причём не обязательно не- 
посредственно (face-to-face) в офлайне, но и с помощью трансфера соответствующих сообщений компьютером в онлайне. Все мы, даже взрослые и вполне самодостаточные люди, нуждаемся в оценке (лучше позитивной) других людей, а не «бездушного компьютера», пусть даже именуемого искусственным интеллектом. Хотя негативная оценка психологически более щадяща именно от компьютера.

Автоматизированные компьютерные обратные связи проще всего сконструировать в тестах электронных учебников, для заданий инженерных тренажёров - там, где есть возможность формализовать оценку результата решения теста или выполнения задания. Но, например, для заданий типа эссе в гуманитарных онлайн-курсах автоматизировать процесс оценки - весьма нетривиальная задача. То же относится и ко многим сферам учебной проектной работы. В частности, при использовании систем автоматизации профессиональной деятельности даже хорошо обученный искусственный интеллект не всегда может быть полезен.

В массовых онлайн-курсах, в частности в MOOK, определённые надежды возлагают на взаимопроверку и взаимопомощь учащихся [15]. Чаще всего преподаватель-тьютор не в состоянии взаимодействовать более чем с несколькими десятками учащихся, если, конечно, курс представляет собой не учебное пособие и итоговый тест, а состоит из набора модулей не только с промежуточными тестами, но и другими формами учебной деятельности по каждому из них. Ведь именно общение учащихся в ходе учебной деятельности по освоению курса является Аидактической «изюминкой» МООК. При реализации концепции равноправного (peerto-peer) обучения учащиеся нередко объясняют учебный материал друг другу, выполняя тем самым важную для себя учебную работу по его осмыслению и закреплению в соответствии с собственным опытом и когнитивными возможностями. Однако и здесь не всё так просто.
Аело в том, что подобные формы учебной деятельности в онлайн-курсе тоже надо как-то организовывать. Так, эксперименты авторов при внедрении взаимной проверки и оценивания заданий в онлайн-курсе самими обучающимися на межвузовском ФПКП показывают, что даже при небольшом числе обучающихся это отнюдь не просто [15]. Возможный выход - формализация и автоматизация процедур объединения учащихся в микроколлективы для выполнения проектной работы, процедур организации взаимной проверки и оценивания, в том числе и стимулирование этих видов учебной работы. Однако всё это неизбежно тянет за собой жёсткую регламентацию, в частности, по срокам, за что нередко критикуют «золотые клетки» современных виртуальных сред [16].

Ещё одно направление автоматизации процесса создания трудноформализуемых обратных связей - использование больших данных и алгоритмов искусственного интеллекта (ИИ). Обратные связи в ЭОИС в совокупности с реакциями на них учащихся и преподавателей являются основой «цифровых следов», по которым алгоритмы ИИ могут проектировать индивидуальные траектории обучения для каждого учащегося, формировать базы типовых реакций (обратных связей) экспертов-преподавателей, обучать программы ИИ оказывать консультативную помощь учащимся в ходе решения учебных задач, а преподавателям - в процессе корректировки обучающих программ.

\section{Выводы}

1. Вопросы формирования структуры и развития ЭОИС ОУ целесообразно рассматривать с системных позиций, включая такие важные составляющие, как подсистема маркетинга, комплекс технических средств, различные виды обеспечения и организационная подсистема.

2. В проблематике ЭОИС ОУ весьма значимыми являются дидактические аспекты проектирования и функционирования 
цифровых образовательных ресурсов, различные виды которых целесообразно интегрировать в комплексы, обеспечивающие полноценную проработку учебного материала на разных целевых уровнях усвоения от первоначального знакомства до решения нетиповых профессионально ориентированных задач.

3. Большое значение в решении вопросов управления учебным процессом в ЭОИС ОУ имеют поступающие в ответ на действия учащихся отклики от преподавателей, других учащихся и обучающих программ, которые в педагогических системах принято называть обратными связями. При этом автоматизация процесса формирования обратных связей в различных компонентах ЭИОС делает когнитивную деятельность учащихся в существенной мере самостоятельной и эффективной.

4. Обратные связи в ЭОИС ОУ в совокупности с реакциями на них учащихся и преподавателей являются основой «цифровых следов», по которым алгоритмы искусственного интеллекта могут проектировать индивидуальные траектории обучения для каждого учащегося, формировать базы типовых обратных связей экспертов-преподавателей, обучать программы искусственного интеллекта оказывать консультативную помощь учащимся в ходе решения учебных задач, а преподавателям - в процессе корректировки обучающих программ.

\section{$\Lambda$ итература}

1. Бродовская Е.В., Аомбровская А.Ю., Пеmрова Т.Э., Пььма Р.В., Азаров А.А. Цифровая среда ведущих университетов мира и РФ: результаты сравнительного анализа данных сайтов // Высшее образование в России. 2019. T. 28. № 12. C. 9-22. DOI: https://doi. org/10.31992/0869-3617-2019-28-12-9-22

2. МакЭндрю К. Укрощение инноваций: как онлайн-магистратура вернула университету инициативу в преобразованиях // Вопросы образования. 2018. № 4 (Специальный выпуск по итогам Международной научной конференции «eLearning Stakeholders and
Researchers Summit 2017» (eSTARS)). C. 60-80. DOI: http://doi.org/10.17323/1814-9545-20184-60-80

3. Соловов А.В. Технические средства САПР: Учебное пособие. Куйбышев: КуАИ, 1987. $135 \mathrm{c.}$

4. Аяченков Н.В., Кокотов В.Я., Соловов А.В. Информационные технологии в системе качества АО “АвтоВАЗ” // Стандарты и качество. 1997. № 12. C. 40-43.

5. Соловов А.В. Проектирование компьютерных систем учебного назначения: Учебное пособие. Самара : СГАУ, 1995. 140 с.

6. Sclater $N$. E-education in the cloud // International Journal on virtual management systems and individual learning. 2010. Vol. 1. No. 1, January-March. P. 10-19. DOI: https://doi. org/10.4018/jvple.2010091702

7. Соловов А.В. Подготовка персонала для виртуальных учебных сред // Высшее образование в России. 2009. № 10. С. 32-36.

8. Полани М. Аичностное знание. На пути посткритической философии : Пер. с англ. М.: Прогресс, 1985. 349 с.

9. Шрейдер Ю.А. Экспертные системы: их возможности в обучении // Вестник высшей школы. 1987. № 2. С. 14-19.

10. Спенсер А.М., Спенсер С.М. Компетенции на работе. Модели максимальной эффективности работы: Пер. с англ. М.: НIPPO, 2005. $384 \mathrm{c.}$

11. Кузин А.П. Основы кибернетики: В 2 т. Т. 2. Основы кибернетических моделей: Учебное пособие для вузов. М.: Энергия, 1979. $584 \mathrm{c}$.

12. Соловов А.В. Электронное обучение: проблематика, дидактика, технология. Самара : Новая техника, 2006. 464 с.

13. Комаров В.А., Соловов А.В. АОС и инженерная интуиция // Вестник высшей школы. 1986. N 2. C. 30-33.

14. Швари И.Е. Педагогика школы. Пермь: ПГПИ, 1968.

15. Соловов А.В., Меньшикова А.А. Электронное обучение: вектор развития // Высшее образование в России. 2015. № 11. С. 66-75.

16. Соловов А.В. «Золотые клетки» виртуальных учебных сред // Высшее образование в России. 2012. № 11. С. 133-137.

Статья поступила в редакцию 15.09.20

Принята к публикачии 18.12.20 


\section{References}

1. Brodovskaya, E.V., Dombrovskaya, A.Yu., Petrova, T.E., Pyrma, R.V., Azarov, A.A. (2019). Digital Space of Leading Universities: The Comparative Analysis of Sites. Vysshee obrazovanie $v$ Rossii $=$ Higher Education in Russia. Vol. 28, no. 12, pp. 9-22, doi: https://doi. org/10.31992/0869-3617-2019-28-12-9-22 (In Russ., abstract in Eng.).

2. McAndrew, Q. (2018). Innovation Leashed: How a MOOC-Based Master's Degree Brings Invention Home to the Institution. Voprosy obrazovaniya = Educational Studies Moscow. No. 4. (Special Edition Following the International Scientific Conference «eLearning Stakeholders and Researchers Summit 2017» (eSTARS)), pp. 60-80, doi: http://doi.org/10.17323/1814-95452018-4-60-80

3. Solovov, A.V. (1987). Tekbnicheskie sredstva SAPR: Uchebnoe posobie [CAD Technology: Training Manual]. Kuibyschev: KuAI Publ., 135 p. (In Russ.).

4. Lyachenkov, N.V., Kokotov, V.Y., Solovov, A.V. (1997). Information Technology in the Quality System of Avtovaz. Standarty i kachestvo = Standards and Quality. No. 12, pp. 40-43. (In Russ.).

5. Solovov, A.V. (1995). Proektirovanie komputernykh sistem uchebnogo naznachenia: Uchebnoe posobie [Designing Computer Systems for Training Purposes: Training Manual]. Samara: SSAU Publ., 140 p. (In Russ.).

6. Sclater, N. (2010). E-Education in the Cloud. International Journal on Virtual Management Systems and Individual Learning. Vol. 1, no. 1, pp. 10-19, doi: https://doi.org/10.4018/jvple.2010091702

7. Solovov, A.V. (2009). Training Staff for Virtual Learning Environments. Vysshee obrazovaniev Rossii = Higher Education in Russia. No. 10, pp. 32-36. (In Russ., abstract in Eng.).

8. Polanyi, M. (1962). Personal Knowledge. Towards Post-Critical Pbilosophy. Chicago: The University of Chicago Press. (Russian Translation M.B. Gnedovskyi, Moscow: Progress Publ., 1985, 349 p.).

9. Shreider, Yu.A. (1987). Expert Systems: Their Learning Opportunities. Vestnik Vysshey Schooly = Higher School Herald. No. 2, pp. 14-19. (In Russ.).

10. Spencer, L.M., Spencer, S.M. (1993). Competence at Work. Models for Superior Performance. John Wiley \& Sons, Inc. ISBN: 978-0-471-54809-6, 384 p. (Russian Translation A. Yakovenko, Moscow: HIPPO Publ., 2005, 384 p.).

11. Kuzin, L.P. (1979). Osnovy kibernetiki: V 2-kb t. T. 2. Osnovy kiberneticheskikb modelei: Uchebnoe posobie dlya vuzov [Basics of Cybernetics. The Basics of Cybernetic Models: A Textbook for Universities]. Vol. 2. Moscow: Energiya Publ., 584 p. (In Russ.).

12. Solovov, A.V. (2006). Elekronnoe obuchenie: problematika, didaktika, tekbnologiya [E-Learning: Problems, Didacticism, Technology]. Samara: Novaya Tekhnika Publ., 464 p. (In Russ.).

13. Komarov, V.A., Solovov, A.V. (1986). [Automated Training System and Engineering Intuition]. Vestnik Vysshey Schooly = Higher School Herald. No. 2, pp. 30-33. (In Russ.).

14. Shvarts, I.E. Pedagogika Shkoly [School Pedagogy]. Perm: PGPU Publ., 1968. (In Russ.).

15. Solovov, A.V., Menshikova, A.A. (2015). E-Learning: Development Vector. Vysshee obrazovanie v Rossii = Higher Education in Russia. No. 11, pp. 66-75. (In Russ., abstract in Eng.).

16. Solovov, A.V. (2012). «Gold Cells» of Virtual Learning Environments. Vysshee obrazovanie v Rossii = Higher Education in Russia. No. 11, pp. 133-137. (In Russ., abstract in Eng.). 